\title{
Efficacy of 2 Drops versus 3 Drops Proparacaine 0.5\% Ophthalmic Solution for Phacoemulsification Surgery: A Comparative Study
}

\author{
Tanie Natung, Jacqueline Syiem, Avonuo Keditsu, Nilotpal Saikia, Ranendra Hajong, \\ Laura Amanda Lyngdoh
}

North Eastern Indira Gandhi Regional Institute of Health \& Medical Sciences, Shillong, India

Email: natungtanie@gmail.com

Received 26 April 2015; accepted 31 July 2015; published 4 August 2015

Copyright (C) 2015 by authors and Scientific Research Publishing Inc.

This work is licensed under the Creative Commons Attribution International License (CC BY). http://creativecommons.org/licenses/by/4.0/

(c) (†) Open Access

\section{Abstract}

Background and Aim: Phacoemulsification surgery with intraocular lens implantation is routinely done under topical anaesthesia in many centres. No comparative study on the efficacy of number of drops of topical anaesthetics effective for phacoemulsification surgery has been done. This study was conducted to compare the efficacy of 2 drops versus 3 drops proparacaine $0.5 \%$ ophthalmic solution for phacoemulsification surgery. Methods: Patients with uncomplicated cataract undergoing phacoemulsification surgery were randomised into two groups. Group $1(n=53)$ received 3 drops of proparacaine $0.5 \%$ whereas group $2(n=47)$ received 2 drops of the same solution before the start of surgery. All the patients underwent phacoemulsification with foldable intraocular lens implantation. Each patient's subjective experience of pain was measured using a 10 point Visual Analogue Pain Scale (VAS). Patient's cooperation during the surgery was assessed using a 3 point score. Both the evaluating resident doctor and patients were blinded. Results: In group 1, 73.6\% patients scored $0,20.8 \%$ scored 1 and $5.7 \%$ scored 2 of VAS respectively and in group $2,89.4 \%, 6.4 \%, 4.3 \%$ patients scored 0,1 and 2 of VAS respectively. In patient cooperation, $90.1 \%$ and $9.4 \%$ patients in group 1 scored 1 and 2 respectively whereas $87.2 \%$ and $12.8 \%$ patients scored 1 and 2 respectively in group 2 . No statistically significant difference in the mean VAS $(P=0.0 .55)$ and patient cooperation score $(P=0.597)$ was found between the two groups. The mean VAS score was $1.24 \pm 0.534$ and the mean patient cooperation score was $1.11 \pm 0.314$. The mean total surgical time was $25.11 \pm 2.68$ minutes. No additional drops were required for either group. Conclusions: Topical anaesthesia with both 2 drops and 3 drops proparacaine $0.5 \%$ ophthalmic solution is effective for phacoemulsification with intraocular lens implantation. Additional 
anaesthesia may be unnecessary in these cases.

\section{Keywords} Topical Anaesthesia, Proparacaine 5\% Ophthalmic Solution, Phacoemulsification Surgery, Visual
Analogue Pain Scale

\section{Introduction}

Clear corneal phacoemulsification with intraocular lens (IOL) implantation under topical anaesthesia is a standard practice today in many centres. However, prolonged doses of local anaesthetic agents can be toxic to the corneal epithelium. High or repeated doses can impair wound healing and cause corneal erosion [1]. Some patients may even be allergic to certain topical medications. Surgery under topical anesthesia may be rendered more difficult by repeated administration of topical medications which causes clouding of cornea [1]. Topical anaesthetic can also cause irritation to the eyes. Therefore, a minimal number of drops of topical anaesthetic agents effective for phacoemulsification surgery will help in reducing the toxicity.

Many studies on the effectiveness of anesthesia for cataract surgeries have been carried out using the Visual Analogue Pain Scale (VAS) [2]. Although No-anesthesia clear corneal phacoemulsification [3] and phacoemulsification with a single drop proparacaine hydrochloride [4] have been done, no comparative study on the efficacy of number of drops has been done to the best of our knowledge. Therefore, we conducted the present study to evaluate the efficacy of 2 drops versus 3 drops proparacaine $0.5 \%$ ophthalmic solution for phacoemulsification surgery.

\section{Methods}

The study was carried out in a medical college of Northeast India from April, 2013 to September, 2013. It was a prospective, randomised, comparative, interventional study. All the patients underwent anterior segment examination, refraction, applanation tonometry, biometry, dilated funduscopy and syringing of the lacrimal sacs. The inclusion criteria were patients with uncomplicated cataract. The exclusion criteria were patients with allergy to proparacaine, hard nuclear cataract ( $\geq$ Grade 5, Lens Opacification Classification III), uncooperative nature, difficulty in communication, non-dilating pupils, pseudoexfoliation syndrome, inability to understand the VAS and psychiatric disorders. Institute Ethics clearance was taken for the study. All the patients signed an informed written consent. We adhered to the tenets of the declaration of Helsinki.

Preoperatively, all the patients were explained in detail about the 10 point VAS, as used by Stevens in his study [2] (Table 1) and how they should respond according to their subjective experience to pain. Cases were randomised into two groups using computer generated random numbers. Group $1(n=53)$ received 3 drops of proparacaine $0.5 \%$ ophthalmic solution (Paracain, Sunways $P$ Ltd., Mumbai) whereas group $2(\mathrm{n}=47)$ received 2 drops of the same solution before the start of surgery. In group 1, one drop was put just before the cleaning and draping of the patient. The second drop was put after cleaning the conjunctival sac with betadine solution, just before the first corneal incision. The third drop was put after the completion of nucleotomy. In group 2, one drop was put just before the cleaning and draping of the patient. The second drop was put after cleaning the conjunctival sac with betadine solution, just before the first corneal incision. The flow chart of the comparative study design is given in Flow Chart 1. No intracameral or any other additional anesthesia was given. All the surgeries were performed by a single highly experienced and skilled faculty surgeon, who has the experience of performing hundreds of phacoemulsification surgeries with intraocular implantation. All the surgeries were done using clear corneal $2.8 \mathrm{~mm}$ main incision with 2 side ports, anterior continuous curvilinear capsulorrhexis, hydrodissection, phacoemulsification either with divide and conquer or stop and chop technique, irrigation and aspiration, both anterior and posterior capsular polishing, implantation of IOL with foldable lens (Acrysof IQ, Alcon Pvt. Ltd.), irrigation and aspiration again including underneath the IOL and stromal hydration of ports. All the surgeries were done using Laureate phacoemulsifier (Alcon Pvt. Ltd). One drop of preversative free moxifloxacin $0.5 \%$ eye drop $\left(\right.$ Vigamox $\left.^{\circledR}\right)$ was put at the end of the surgery before the removal of the speculum. 


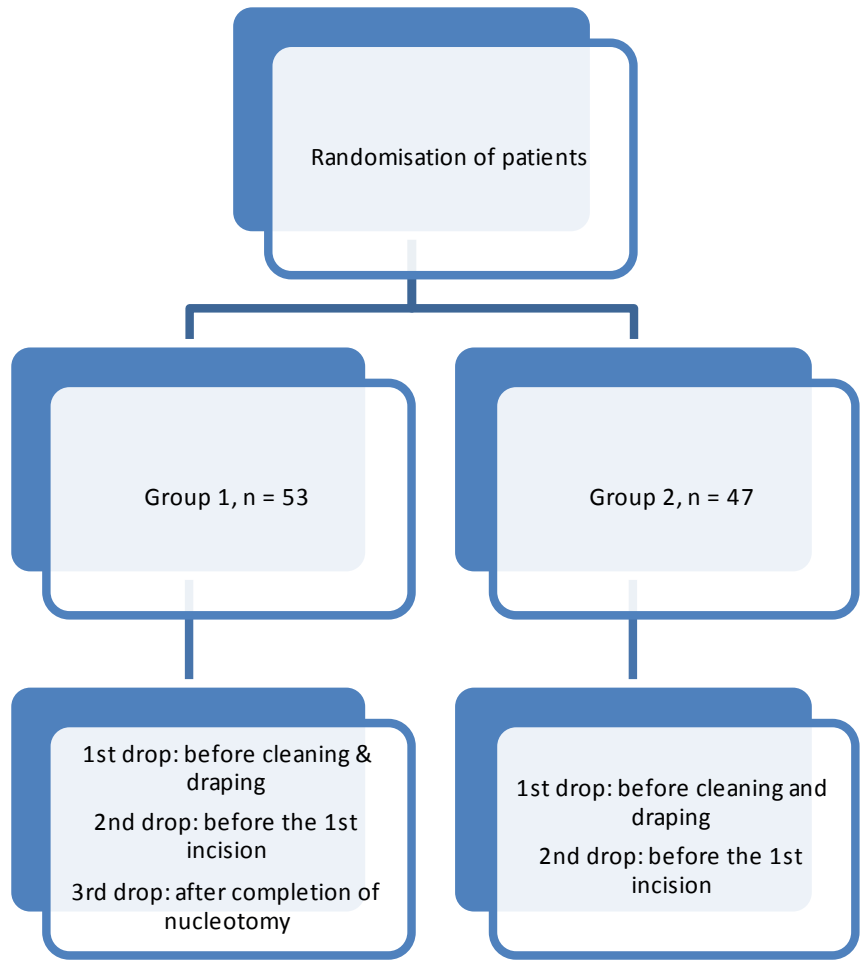

Flow Chart 1. Flow chart of the study design.

Table 1. Visual Analogue Pain Scale.

\begin{tabular}{cc|}
\hline Numerical Scores & Descriptive Score \\
\hline 0 & No Pain \\
1 & Slight Discomfort \\
2 & Slight Pain \\
4 & Light Pain \\
5 & Light to Moderate Pain \\
6 & Moderate Pain \\
7 & Moderate to Severe Pain \\
8 & Severe Pain \\
9 & Very Severe Pain \\
10 & Excruciating Pain \\
\hline
\end{tabular}

Adopted from Stevens JD².

Each patient's subjective experience of overall pain during the surgery was measured using a 10 point VAS [2], 10 minutes after the surgery by a senior resident doctor. Both the resident doctor and the patient were blinded from the number of drops. Patients' cooperation during the surgery was assessed using a 3 point score (Excellent $=1$, Good $=2$, Poor $=3$ ) [5]. The total surgical time in minutes was taken as the duration between the first incision to the removal of speculum.

\section{Statistical Analysis}

Descriptive statistics was used to calculate the mean \pm standard deviation and percentages. Mann Whitney test 
was used to compare the mean pain and patient cooperation scores between the two groups, between genders and between right or left eyes. Similarly, Independent-Samples $t$ test was used to compare the mean surgical time between the two groups, between the genders and between right or left eyes. A P-value of less than 0.05 was considered significant. Statistical analysis was performed using the SPSS software package (SPSS for Windows, version 22.0; SPSS, Inc., Chicago, IL).

\section{Results}

Patient characteristics and scores are shown in Table 2. All the patients had uneventful surgery. In group I, 73.6\% patients scored 0 (no pain), 20.8\% scored 1 (slight discomfort) and 5.7\% scored 2 (slight pain) using the VAS (Figure 1). In group II, 89.4\%, 6.4\%, 4.3\% patients scored 0, 1 and 2 respectively (Figure 2). In patient cooperation, $90.1 \%$ and $9.4 \%$ patients in group 1 scored 1 and 2 respectively whereas $87.2 \%$ and $12.8 \%$ patients scored 1 and 2 in group 2 respectively. No statistically significant difference in the mean patient-reported pain scores for overall pain was found between the two groups $(\mathrm{P}=0.055)$ (Table 3$)$. Similarly, there was no statistically significant difference in the mean patient cooperation for surgery between the two groups $(\mathrm{P}=0.597)$ (Table 3).

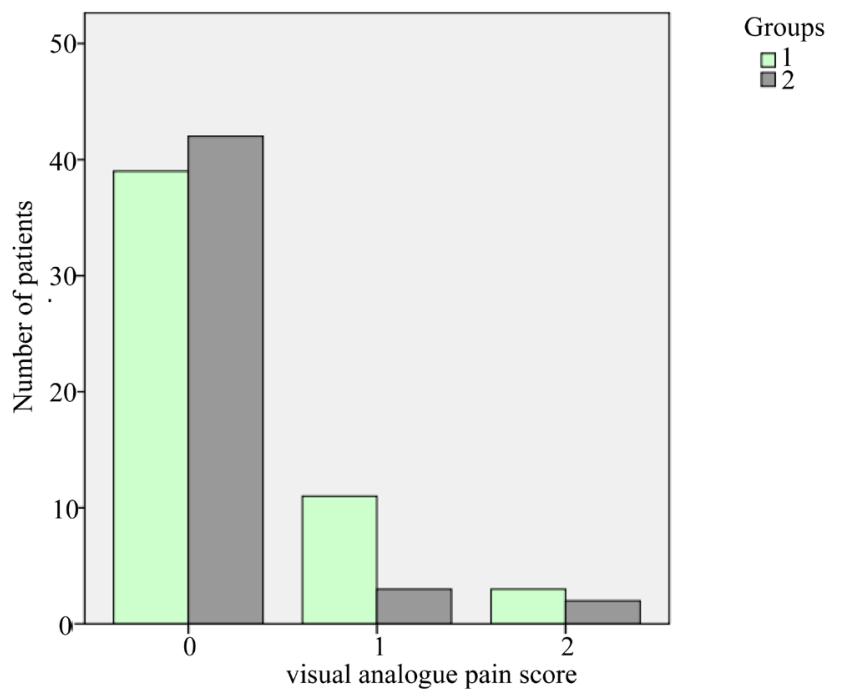

Figure 1. VAS scores recorded for the operative procedures in group 1 and 2.

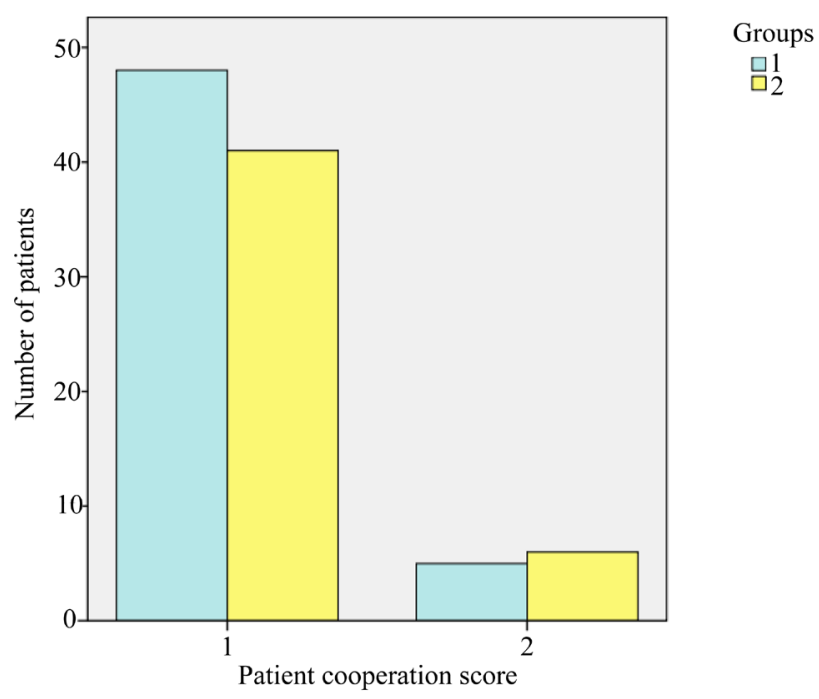

Figure 2. Patient cooperation scores during the procedure in group 1 and 2. 
Table 2. Patient characteristics by groups.

\begin{tabular}{ccc}
\hline Characteristics & Group 1 & Group 2 \\
\hline Number of cases & 53 & 47 \\
Mean age \pm SD (Years) & $63.83 \pm 12.22$ & $57.79 \pm 17.01$ \\
Male/Female & $28 / 25$ & $26 / 21$ \\
Mean total surgical time (minutes) & $24.87 \pm 2.85$ & $25.06 \pm 3.010$ \\
\hline
\end{tabular}

There was no statistically significant difference in the VAS score by gender $(\mathrm{P}=0.500)$ and by right or left eyes $(\mathrm{P}=0.124)$. Similarly, there was no statistically significant difference in the patient cooperation score by gender $(\mathrm{P}=0.969)$ and by right or left eyes $(\mathrm{P}=0.244)$ (Table 3$)$.

The mean VAS score was $1.24 \pm 0.534$ and the mean patient cooperation score was $1.11 \pm 0.314$. The mean surgical time was $25.11 \pm 2.68$ minutes. No additional drops were required for either group.

The mean surgical time was $24.57 \pm 2.85$ and $25.06 \pm 3.01$ minutes in group 1 and 2 respectively. The difference was not statistically significant $(\mathrm{P}=0.739)$ (Table 3$)$. The pain scale core was weakly correlated with the duration of surgery $(\mathrm{P}=0.655)$.

\section{Discussion}

Topical anesthesia in general has been found to be safe and effective for phacoemulsification surgery [4] [6][12]. It has many advantages. It eliminates the risks associated with retrobulbar and peribulbar blocks, as well as the risks associated with general anesthesia [13]. There is faster recovery of postoperative uncorrected visual acuity and the duration of surgery is shorter [11] [14]. It is also more economical as compared with peribulbar, subtenon or retrobulbar anaesthesia [11] [15]. Yet, the level of anesthesia is as good as that of subtenon anesthesia [16] [17]. No significant difference is found in their studies by Kim et al. and Sarkar et al. [16] [17].

Topical anesthesia alone without additional supplementation also has been established to be effective for cataract surgeries. Crandall et al. found that topical anesthesia alone was as good as topical anesthesia plus intracameral lidocaine in providing "good operative conditions for the surgeon and comfortable surgical circumstances for the patient" [18]. Also, there appears to be no difference by gender in the level of pain perception. Gupta el al. found that patients who underwent cataract surgery under topical anesthesia perceive comparable pain and discomforted irrespective of their sex [5]. However, although both topical and intracameral anesthesia appears to be safe for phacoemulsification surgery, they are not totally safe for the ocular structures [19]. Intracameral lignocaine supplement is known to be more effective in decreasing the level of pain, but detailed research is lacking in terms of its toxicity [11] [20]. During short term in-vitro exposure, lidocaine HCL appeared to be safe to both human and rabbit endothelium but further in vivo and vitro studies were suggested by Kim $e l$ al. to determine long-term effects of intraocular lidocaine on the corneal endothelium [21]. In a metanalaysis by Ezra et al., it was found that intracameral lidocaine reduced intra-operative pain during cataract surgery under topical anaesthesia but possible adverse effects of intracameral lidocaine could not be excluded and they had reservations regarding recommending this additional intervention [22].

There have been many studies on the effectiveness and safety of topical anesthesia for phacoemulsification with intraocular lens implantation. However, there has been no comparative study on the number of drops adequate for the procedure. Therefore, our objective was to compare the efficacy of 2 versus 3 drops $0.5 \%$ eye drops for phacoemulsification surgery with intraocular lens implantation. In our study, there was no statistically significant difference in the mean patient-reported pain scores for overall pain between the two groups $(\mathrm{P}=$ 0.055). Similarly, there was no statistically significant difference in the mean patient cooperation for surgery between the two groups $(P=0.597)$. The mean pain score was $1.24 \pm 0.534$ and the mean patient cooperation score was $1.11 \pm 0.314$. There was no difference in the VAS score by gender $(\mathrm{P}=0.500)$. This is in agreement with Gupta et al. [5]. There was also no statistically significant difference in the mean VAS score between right and left eyes $(\mathrm{P}=0.124)$. No additional drops were required for either group.

Different authors have used different anaesthetics for phacoemulsification in their studies and have got different VAS scores. The mean VAS score in the study by Pandey et al. was $1.44 \pm 1.04$ [3]. They used $4 \%$ Xylocaine. It was $4.19 \pm 2.321$ in the study by Tsoumani et al. [7]. They used $0.5 \%$ tetracaine. Similarly, the mean VAS scores were $1.53 \pm 0.29$ and $1.171 \pm 1.50$ in the study by Soliman et al. and Joshi RS respectively [4] [8]. 
Table 3. Parameters and scores.

\begin{tabular}{cccc}
\hline & \multicolumn{2}{c}{ P values } & \\
\cline { 2 - 4 } Parameters & By groups & By gender & By eye \\
\hline Pain scale $(0-10)[2]$ & 0.055 & 0.500 & 0.124 \\
Patient cooperation (0 - 3) [5] & 0.597 & 0.969 & 0.244 \\
Surgical time (minutes) & 0.739 & 0.900 & 0.407 \\
\hline
\end{tabular}

Table 4. Comparison of mean VAS scores and anaesthetics used in different studies.

\begin{tabular}{ccc}
\hline Study & Mean VAS score & Anaesthetics used \\
\hline Pandey et al. [3] & $1.44 \pm 1.04$ & $4 \%$ Xylocaine drop, intracameral Xylocaine. \\
Tsoumani et al. [7] & $4.19 \pm 2.321$ & $0.5 \%$ tetracaine, Lidocaine $2 \%$ gel. \\
Soliman et al. [8] & $1.53 \pm 0.29$ & Lido $2 \%, 0.5 \%$ bupivacaine, Benoxinate $0.4 \%$. \\
Joshi RS [4] & $1.171 \pm 1.50$ & $0.5 \%$ proparacaine drop, $0.5 \%$ intracameral Xylocaine. \\
Present study & $1.24 \pm 0.534$ & $0.5 \%$ proparacaine drops. \\
\hline
\end{tabular}

Soliman et al. used 0.5\% bupivacaine whereas Joshi used 0.5\% proparacaine [4] [8]. In our study, we used 0.5\% proparacaine which was similar to that of Joshi et al. The mean pain score in our study is comparable to the mean pain score found in these similar studies using different topical anesthetics (Table 4).

To conclude, our study has shown that topical anaesthesia with both 2 drops and 3 drops proparacaine $0.5 \%$ ophthalmic solution is effective for phacoemulsification with intraocular lens implantation and that 2 drops of proparacaine are adequate for this procedure. Topical anesthesia is a standard form of anesthesia accepted for phacoemulsification surgery but requires experienced surgeon and faster surgery. Therefore, the choice of anesthesia has to be individualised depending upon the surgeon's experience and operative comfort and taking into account patients' conditions and requirements. It is suggested that to minimise the amount of medication and its toxicity, 2 drops of $0.5 \%$ proparacaine HCL is adequate for phacoemulsification surgery with intraocular lens implantation in routine cases in expert hands. Intracameral anaesthesia or other additional form of anesthesia may be unnecessary in these cases.

\section{References}

[1] Malik, A., Fletcher, E.C., Chong, V. and Dasan, J. (2010) Local Anesthesia for Cataract Surgery. Journal of Cataract \& Refractive Surgery, 36, 133-152. http://dx.doi.org/10.1016/j.jcrs.2009.10.025

[2] Stevens, J.D. (1992) A New Local Anaesthesia Technique for Cataract Extraction by One Quadrant Sub-Tenon’s Infiltration. British Journal of Ophthalmology, 76, 670-674. http://dx.doi.org/10.1136/bjo.76.11.670

[3] Pandey, S.K., Wener, L. and Apple, D.J., et al. (2001) No-Anaesthesia Clear Corneal Phacoemulsification versus Topical and Topical plus Intracameral Anesthesia. Randomized clinical trial. Journal of Cataract \& Refractive Surgery, 27, 16431650. http://dx.doi.org/10.1016/S0886-3350(01)00793-3

[4] Joshi, R.S. (2013) A Single Drop of 0.5\% Proparacaine Hydrochloride for Uncomplicated Clear Corneal Phacoemulsification. Middle East African Journal of Ophthalmology, 20, 221-224. http://dx.doi.org/10.4103/0974-9233.114795

[5] Gupta, S.K., Kumar, A. and Agarwal, S. (2010) Cataract Surgery under Topical Anesthesia: Gender-Based Study of Pain Experience. Oman Journal of Ophthalmology, 3, 140-144. http://dx.doi.org/10.4103/0974-620X.71893

[6] Duguid, I.G.M., Claque, C.M.P., Thamby-Rajah, Y., et al. (1995) Topical Anaesthesia for Phacoemulsification Surgery. Eye, 9, 456-459. http://dx.doi.org/10.1038/eye.1995.106

[7] Tsoumani, A.T., Asproudis, I.C. and Damigos, D. (2010) Tetracaine 0.5\% Eyedrops with or without Lidocaine 2\% Gel in Topical Anesthesia for Cataract Surgery. Journal of Clinical Ophthalmology, 4, 967-970. http://dx.doi.org/10.2147/OPTH.S11755

[8] Soliman, M.M., Macky, T.A. and Samir, M.K. (2004) Comparative Clinical Trial of Topical Anesthetic Agents in Cataract Surgery: Lidocaine 2\% Gel, Bupivacaine 0.5\% Drops and Benoxinate 0.4\% Drops. Journal of Cataract \& Refractive Surgery, 30, 1716-1720. http://dx.doi.org/10.1016/j.jcrs.2003.12.034 
[9] Waheeb, S. (2010) Topical Anesthesia in Phakoemulsification. Oman Journal of Ophthalmology, 3, 136-139. http://dx.doi.org/10.4103/0974-620X.71892

[10] O’Brian, P.D., Fulcher, T., Wallace, D. and Power, W. (2001) Patient Pain during Different Stages of Phacoemulsification Using Topical Anesthesia. Journal of Cataract \& Refractive Surgery, 27, 880-883. http://dx.doi.org/10.1016/S0886-3350(00)00757-4

[11] Hasan, S.A., Edelhauser, H.F. and Kim, T. (2001) Topical/Intracameral Anesthesia for Cataract Surgery. Survey of Ophthalmology, 46, 178-181. http://dx.doi.org/10.1016/S0039-6257(01)00248-X

[12] Patel, B.C., Burns, T.A., Crandall, A., Shomaker, S.T., Pace, N.L., van Eerd, A. and Clinch, T. (1996) A Comparison of Topical and Retrobulbar Anesthesia for Cataract Surgery. Ophthalmology, 8, 1196-1203. http://dx.doi.org/10.1016/S0161-6420(96)30522-8

[13] Oberg, T.J., Sider, S., Jorgensen, A.J. and Mifflin, M.D. (2012) Topical-Intracameral Anesthesia without Preoperative Mydriatic Agents for Descemet-Stripping Automated Endothelial Keratoplasty and Phacoemulsification Cataract Surgery with Intraocular Lens Implantation. Journal of Cataract \& Refractive Surgery, 38, 384-386. http://dx.doi.org/10.1016/j.jcrs.2011.12.025

[14] Rizvi, Z., Rehman, T., Malik, S., Qureshi, A., Paul, L., Qureshi, K., et al. (2003) An Evaluation of Topical and Local Anesthesia in Phacoemulsification. Journal of Pakistan Medical Association, 53, 167-170.

[15] Monestam, E., Kusik, M. and Wachtmeister, L. (2001) Topical Anesthesia for Cataract Surgery: A Population-Based Perspective. Journal of Cataract \& Refractive Surgery, 27, 445-451. http://dx.doi.org/10.1016/S0886-3350(00)00637-4

[16] Kim, M.J. and Jain, S. (2013) What Makes a Good Operation Great? Factors Determining Patient Satisfaction with Local Anaesthesia in Cataract Surgery. Eye, 27, 1114. http://dx.doi.org/10.1038/eye.2013.125

[17] Sarkar, S., Maiti, P., Nag, S., Sasmal, N.K. and Biswas, M. (2010) Changing Trends of Ocular Anaesthesia in Phacoemulsification Surgery. Journal of Indian Medical Association, 108, 823-825.

[18] Crandall, A.S., Zabriskie, N.A., Patel, B.C., Burns, T.A., Mamalis, N., Malmquist-Carter, L.A. and Yee, R. (1999) A Comparison of Patient Comfort during Cataract Surgery with Topical Anesthesia versus Topical Anesthesia and Intracameral Lidocaine. Ophthalmology, 106, 60-66. http://dx.doi.org/10.1016/S0161-6420(99)90007-6

[19] Shah, R. (2010) Anesthesia for Cataract Surgery: Recent Trends. Oman Journal of Ophthalmology, 3, 107-108. http://dx.doi.org/10.4103/0974-620X.71881

[20] Lofoco, G., Ciucci, F., Bardocci, A., Quercioli, P., De Gaetano, C., Ghirelli, G., et al. (2008) Efficacy of Topical plus Intracameral Anesthesia for Cataract Surgery in High Myopia: Randomised Controlled Trial. Journal of Cataract Refractive Surgery, 34, 1664-1668. http://dx.doi.org/10.1016/j.jcrs.2008.06.019

[21] Kim, T., Holley, B.S., Lee, J.H., Broocker, G. and Edelhauser, H.F. (1998) The Effects of Intraocular Lidocaine on the Corneal Endothelium. Ophthalmology, 105, 125-130. http://dx.doi.org/10.1016/S0161-6420(98)91666-9

[22] Ezra, D.G., Nambiar, A. and Allan, B.D. (2008) Supplementary Intracameral Lidocaine for Phacoemulsification under Topical Anesthesia: A Meta-Analysis of Randomized Controlled Trials. Ophthalmology, 115, 455-487. http://dx.doi.org/10.1016/j.ophtha.2007.09.021 